Revista de Derecho Político, núm. 33, 1991, pp. 239-248

\title{
CRÓNICA PARLAMENTARIA DEL CONGRESO DE LOS DIPUTADOS
}

POR

PILAR MELLADO PRADO

Profesora Titular de Derecho Constitucional

UNED

La presente Crónica parlamentaria comprende la actividad desarrollada por la Cámara Baja durante los meses de mayo y junio de 1990, en la IV Legislatura constitucional.

I. ACTIVIDAD LEGISLATIVA

1. Proyectos de Ley

\begin{tabular}{cc}
\hline & BOCG, \\
MATERIA & $\mathrm{A}, \mathrm{n} .^{\circ}$ \\
\end{tabular}

De ordenación general del sistema 
Para adaptar el Derecho español a la Directiva $88 / 357 /$ CEE sobre libertad de servicios en seguros distintos al de vida, y de actualización de la legislación de seguros privados

De modificación de los Códigos Civil y Penal en materia de responsabilidad civil del profesorado

Sobre negociación colectiva y participación en la determinación de las condiciones de trabajo de los empleados públicos

Por el que se crea el Instituto Cervantes

Orgánica de publicidad electoral en emisoras de Radiodifusión sonora municipales

De organización y control de los emisores de Radiodifusión sonora municipales

Sobre derechos de información de los representantes de los trabajadores en materia de contratación

Sobre potestades administrativas en materia de espectáculos taurinos

\section{Aprobado en Comisión con competencia legis- lativa plena. Pendiente de la aprobación del Senado.}

Aprobado por el Pleno. DSC n. ${ }^{\circ} 48$

Tramitado en lectura única y aprobado por el pleno. DSC n. 43 y 45.

Pendiente del Informe de la Comisión de Asuntos Exteriores

Pendiente del Informe de la Comisión Constitucional

Pendiente del Informe de la Comisión Constitucional

Pendiente del Dictamen de la Comisión de Política Social y Empleo 


\section{Proposiciones de Ley}

MATERIA

BOCG, GRUPO

$\mathrm{B}, \mathrm{n}^{\circ} \quad$ PROPONENTE

INCIDENCIAS

De modificación de la Ley $91 / 1978$ de 28 de diciembre, del Parque Nacional de Doñana

Orgánica de modificación de los artículos 412,415 y 702 de la Ley de Enjuiciamiento Criminal

Por la que se da nueva redacción al art. 591 del Código Civil

De supresión de la figura de Gobernador civil y de reforma de la ley que desarrolla el art. 154 de la Constitución

Relativa al nombramiento del Fiscal General del Estado

Sobre modificación de la Ley $17 /$ 1989 de 19 de julio, reguladora del personal militar profesional

Relativa a la modificación del art. 86 de la Ley General de Sanidad

Sobre modificación de la Ley 53/ 1984 de 26 de diciembre, de incompatibilidades del personal al servicio de las Administraciones Públicas
36

Popular

Rechazada

DSC n. ${ }^{\circ} 46$

38

Catalán

39

Vasco

40

Vasco

41

Popular

42

Mixto

43

Popular

44

Popular 
MATERIA

BOCG,

$\mathrm{B}, \mathrm{n}^{\circ}$

GRUPO

PROPONENTE

INCIDENCIAS

Orgánica de modificación de la Ley

45

Popular

Orgánica 2/1979 de 3 de octubre,

del Tribunal Constitucional

Por la que se modifica el texto refundido de la Ley de Arrenda-

46

Catalán mientos Urbanos para facilitar la eliminación de barreras arquitectónicas para arrendatarios con minusvalías

2.1. Proposiciones de Ley de Comunidades Autónomas

$\begin{array}{ccc}\text { BOCG, } & \text { PARLAMENTO } \\ \text { MATERIA } n .^{\circ} & \text { AUTONÓMICO }\end{array}$

Sobre la Ley estatal 9/1988 de 21 de abril, de Planta y Organización territorial de la Jurisdicción militar

De declaración de Parque Nacional y reserva integral de Cabrera

Orgánica de transferencias a la C.A. de Baleares de las competencias de titularidad en materia de protección y tutela de menores

De modificación del art. 487 del Código Penal

1
Cortes de Ara- Rechazada DSC gón $n .^{\circ} 23$

2

Islas Baleares

Tomada en consideración.

DSC n. ${ }^{\circ} 40$

$3 \quad$ Islas Baleares

$4 \quad$ Cataluña 
MATERIA

BOCG, PARLAMENTO

$\mathrm{B}$, n. $^{\circ} \quad$ AUTONOMICO

INCIDENCIAS

Sobre inclusión de la variante de Pajares en el nuevo Plan de Transporte Ferroviario

De modificación del Anexo I de la Ley $38 / 1988$ de 28 de diciembre, de demarcación y Planta judicial

Acuerdo de reforma del Estatuto de Castilla y León
5 Junta General de Asturias

$19 \quad$ Madrid

E,02 Castilla y León

\section{ACTIVIDAD FINANCIERA}

\section{Actividad tributaria}

\begin{tabular}{lccc}
\hline MATERIA & $\begin{array}{c}\text { BOCG, } \\
\text { serie, } \text { n. }^{\circ}\end{array}$ & PROPONENTE & INCIDENCIAS \\
\hline $\begin{array}{l}\text { Por el que se modifica parcialmen- } \\
\text { te la ley 42/1983 de 28 de diciem- } \\
\text { bre reguladora de la cesión de } \\
\text { tributos a la C.A. de Madrid }\end{array}$ & A, 22 & Gobierno & $\begin{array}{c}\text { Aprobado por } \\
\text { Comisión } \\
\text { con c.l. p. }\end{array}$ \\
$\begin{array}{l}\text { Regulación de los beneficios fis- } \\
\text { cales aplicables al conjunto de } \\
\text { las actividades que integran la } \\
\text { organización y celebración en } \\
\text { Madrid de la capital europea de } \\
\text { la cultura de 1992 }\end{array}$ & & & \\
\end{tabular}

\section{Ordenación general o singular de la economía}

Por el que se aprueba el arbitrio sobre la producción y la importaA,24 Gobierno ción en las ciudades de Ceuta y Melilla 


\section{ACTIVIDAD DE CONTROL}

\section{Actos de control sin eficacia jurídica}

1.1. PROPOSICIONES NO DE LEY

a) En Comisión

\begin{tabular}{|c|c|c|c|}
\hline MATERIA & $\begin{array}{c}\text { BOCG, } \\
\mathrm{B}, \mathbf{n} .^{\circ}\end{array}$ & $\begin{array}{c}\text { GRUPO } \\
\text { PROPONENTE }\end{array}$ & INCIDENCIAS \\
\hline
\end{tabular}

Sobre implantación del salario social en el conjunto del Estado

Relativa a la educación permanente de adultos

Por la que se insta al Gobierno a la creación de un servicio de guarda-costas que unifique las competencias en materia de vigilancia sobre aguas jurisdiccionales españolas

Por la que se insta al presidente del CGPJ a tomar las medidas necesarias para que se evite en las resoluciones judiciales la inclusión de argumentos morales, sociales y sexuales que signifique una discriminación o situación vejatoria para las mujeres
$48 \quad$ Mixto

52

Socialista

Aprobada sin modificaciones

63

IU-IC

Rechazada

76

IU-IC

Aprobada con modificaciones 


\begin{tabular}{|c|c|c|}
\hline MATERIA & $\begin{array}{c}B O C G, \\
B, n .\end{array}$ & $\begin{array}{c}\text { GRUPO } \\
\text { PROPONENTE }\end{array}$ \\
\hline
\end{tabular}

b) En Pleno

Por la que se insta al Gobierno a reconocer a Lituania como país independiente

Por la que se acuerda la creación de una comisión para la elaboración de un informe sobre la situación del tráfico y del transporte en las ciudades españolas

Sobre la unidad política europea

Por la que se insta al Gobierno a la modificación del vigente Reglamento de Armas y Explosivos

Sobre la situación en Lituania y la URSS

Por la que se reprueba al Vicepresidente del Gobierno y se insta al Presidente a que lo cese en su cargo

Por la que se insta al Gobierno para que en el plazo de tres meses envie a la Cámara un proyecto de ley por el que se modifique la ley 48/1984, de 26 de diciembre, que regula la objeción de conciencia y la prestación social sustitutoria
59

Socialista

59

47

Mixto

Rechazada

DSC n. ${ }^{\circ} 40$

47

IU-IC

55

IU-IC

59

Mixto

62

Vasco
Aprobada por

el Pleno

DSC n. ${ }^{\circ} 40$ 
MATERIA

Por la que se acuerda la creación de una comisión de seguimiento de la organización y obras de los juegos olímpicos de Barcelona en 1992

Por la que se acuerda la creación de una Comisión de Seguimiento de la organización y obras de la Expo'92 y de las actividades de la Sociedad estatal V Centenario del Descubrimiento de América

Por la que se acuerda la constitución en el seno de la Comisión de Justicia e Interior, de una Ponencia sobre la situación del juego en España

Por la que se insta al Gobierno a adoptar, en el plazo de tres meses, determinadas medidas en relación con los ciudadanos andaluces que, hasta 1964, se desplazaban a Gibraltar a trabajar

Relativa al desarrollo de la Ley de Propiedad Intelectual

Por la que se insta al Gobierno para que, en el plazo máximo de tres meses, presente a la Cámara un proyecto de reforma legal en virtud del cual desaparezca definitivamente la pena de muerte del Ordenamiento jurídico español
62

Popular

Rechazada.

DSS n. ${ }^{\circ} 55$

62

Popular

62

Socialista

Aprobada

DSC n. ${ }^{\circ} 43$

65

Mixto

71

Socialista

Aprobada

DSC n. ${ }^{\circ} 46$

$71 \quad$ Mixto 
MATERIA

BOCG,

GRUPO

$\mathrm{B}, \mathrm{n} .^{\circ}$

PROPONENTE

INCIDENCIAS

Relativa a la creación de una ponencia para analizar el grado de cumplimiento y desarrollo de la ley $13 / 1982$, de 7 de abril, de integración social de los minusválidos

Por la que se insta al Gobierno a la realización de un estudio, y su ulterior remisión a la Cámara, acerca de las diferentes circunstancias que concurren en la aplicación de la legislación vigente en materia de interrupción voluntaria del embarazo

\subsection{INTERPELACIONES URGENTES}

Sobre medidas a adoptar para incrementar la cobertura del régimen público de seguridad social, universalizando las contingencias y prestaciones.

Sobre medidas de politica general a adoptar por el Gobierno para paliar la grave situación por la que atraviesa el sector agrario español, como consecuencia de la congelación de los precios de garantía en las tres últimas campañas

Sobre medidas de política interior que piensa adoptar el Gobierno para garantizar los derechos de los guardias civiles como ciudadanos y que aseguren sus funciones como cuerpo policial
75

Catalán

83

Socialista

Aprobada

DSC n. ${ }^{\circ} 55$
66

Vasco

66

Popular

66

$6 \quad$ IU-IC
DSC n. ${ }^{\circ} 41$.

Moción re-

chazada,

DSC n. ${ }^{\circ} 43$

DSC nop.$^{\circ} 41$.
Moción re-
chazada,
DSC $n .^{\circ} 43$

DSC n. ${ }^{\circ} 41$.

Moción re-

chazada,

DSC n. ${ }^{\circ} 43$ 
MATERIA

BOCG,

$B, n$.

GRUPO

PROPONENTE

INCIDENCIAS

Sobre medidas de política general en materia de medio ambiente que piensa adoptar el Gobierno para proteger el medio natural y el cultural

Sobre medidas de politica general para generalizar el régimen de la Seguridad Social en el sector agrario

Sobre medidas de política general $y$ de inmigración que piensa adoptar el Gobierno para promover la regularización de la situación de los inmigrantes extranjeros en España

\subsection{COMISIONES DE INVESTIGACION}

Solicitud de creación de Comisión de investigación (art. 52 RECD), para el estudio de los denominados casos «Guerra» y «Naseiro»
74

Popular

$$
\begin{aligned}
& \text { DSC n. } 44 . \\
& \text { Moción } \\
& \text { aprobada, } \\
& \text { DSC n. } .^{\circ} \cdot 46
\end{aligned}
$$

74

CDS

DSC n. ${ }^{\circ} 44$.

Moción re-

chazada,

DSC $n .{ }^{\circ} 46$

$74 \quad$ IU-IC
DSC n. 44.
Moción
aprobada,
DSC n. ${ }^{\circ} 46$

IU-IC 